\title{
Dietary supplementation of Rosmarinus officinalis L. leaves in sheep affects the abundance of rumen methanogens and other microbial populations
}

\author{
Gabriella Cobellis ${ }^{1,2^{*}}$, Zhongtang Yu², Claudio Forte ${ }^{1}$, Gabriele Acuti ${ }^{1}$ and Massimo Trabalza-Marinucci ${ }^{1}$
}

\begin{abstract}
Background: Rumen microbiome has a great influence on ruminant health and productivity. Different plant extracts have been tested for their ability to modulate the rumen microbiome to improve feed digestion and fermentation. Among the evaluated plant extracts, essential oils, tannins, and saponins appeared to have positive effects on rumen protein metabolism, volatile fatty acids production, and methane and ammonia production.

Methods: The objective of this study was to evaluate the effect of rosemary (Rosmarinus officinalis L.) leaves and essential oils on rumen microbial populations. Four ruminally cannulated sheep were used in a $4 \times 4$ Latin square design fed (21 d/period): 1) a control diet composed of alfalfa hay and concentrate pellet (CTR), 2) CTR supplemented with $7 \mathrm{~g} / \mathrm{d} / \mathrm{sheep}$ of rosemary essential oil adsorbed on an inert support (EO), 3) CTR with $10 \mathrm{~g} / \mathrm{d} / \mathrm{sheep}$ of dried and ground rosemary leaves (RL), and 4) CTR with $10 \mathrm{~g} / \mathrm{d}$ of dried and ground rosemary leaves pelleted into concentrate (RL pellet). Abundance of total bacteria, archaea, protozoa, and some select bacterial species or groups was quantified using qPCR, while the community of bacteria and archaea was profiled using denaturing gradient gel electrophoresis.

Results: No difference in abundance was noted for total bacteria, protozoa, or Ruminococcus flavefaciens between the control and the treatments, but the rosemary leaves, either in loose form or in pellet, decreased the abundance of archaea and the genus Prevotella $(P<0.001)$. The rosemary leaves in loose form also decreased $(P<0.001)$ the abundance of Ruminococcus albus and Clostridium aminophilum, while the EO increased $(P<0.001)$ the abundance of Fibrobacter succinogenes. The community of bacteria and archaea was not affected by any of the supplements.

Conclusions: Being able to affect the abundance of several groups of rumen microbes that are known to be involved in degradation of protein and fiber and production of methane and ammonia, rosemary leaves may be used to modulate rumen microbiome and its function.
\end{abstract}

Keywords: Archaea, Essential oil, Plant extracts, Rosemary, Rumen microbiome

\section{Background}

The ruminant livestock sector contributes significantly to global emission of greenhouse gas (GHG) as methane and nitrous oxide, the latter of which is produced from the nitrogen (as urea and ammonia) excreted by ruminant animals $[1,2]$. Both the methane and nitrogen

\footnotetext{
* Correspondence: cobellis.gabriella@gmail.com

${ }^{1}$ Department of Veterinary Medicine, University of Perugia, via S. Costanzo 4, 06126 Perugia, Italy

${ }^{2}$ Department of Animal Sciences, The Ohio State University, 2029 Fyffe Road, Columbus, OH 43210, USA
} outputs also represent a loss of dietary energy and nitro-
gen, which are otherwise redirected to animal producSeveral compounds or substances have been tested as dietary supplements for their ability to modulate the composition and metabolic activities of rumen microbiome and to mitigate methane emission and nitrogen excretion from ruminant animals $[1,2]$. Among them, plant extracts, such as essential oils, tannins, and saponins, seem to have positive effects on rumen protein tion. Both methane emission and nitrogen excretion 
metabolism, volatile fatty acids (VFA) production, methane and ammonia production [3-5]. However, the dilemma is that they often exert adverse effects on feed intake, digestion, and rumen fermentation when added at concentrations high enough to achieve substantial or desirable reduction in methane production, while they have little effect when added at permissive concentrations that do not reduce animal productivity [2]. New dietary intervention strategies are being sought after, including using combinations of different inhibitors that have additive inhibition to methane production by rumen microbiome [6, 7].

Rosemary (Rosmarinus officinalis L.) is an evergreen perennial shrub belonging to the Lamiaceae family and rosemary leaves are commonly used as a food seasoning. The secondary metabolites in rosemary are well known, with major compounds including monoterpenoids, such as $\alpha$-pinene, $\beta$-pinene, camphene, $1-8$ cineole, camphor, borneol, bornyl acetate and verbenone, and phenolic diterpenes, such as carnosol, carnosic acid, rosmanol, epirosmanol, isorosmanol, methyl carnosate, and rosmarinic acid [8]. Some of these compounds have antimicrobial and antioxidant activities. Several studies have evaluated rosemary essential oil as feed additive using in vitro rumen fermentation [9-13], but these studies focused on the effect on feed digestion, not methane production or ammonia production. In a previous study using sheep [8], the authors found that rosemary leaves pelleted into concentrate (RL pellet) contained less phenols, but more flavonoids, rosmarinic acid, and total antioxidant activity than the same rosemary leaves that were not pelleted (RL) and rosemary essential oil. Carnosic acid was detected in the RL pellet and the RL diets, but not rosemary essential oil. Rumen $\mathrm{pH}, \mathrm{VFA}$, and lactic acid concentrations of the sheep were not affected by RL, RL pellet, or rosemary essential oil, but CP and DM degradability and ammonia concentration (a tendency) were decreased by RL pellet [8]. The objective of this study was to evaluate the two forms of rosemary leaves (RL and RL pellet) and rosemary essential oil for their effect on select rumen bacterial populations and methanogens.

\section{Methods}

\section{Animals, diets, experimental design, and sampling}

The animals, diet, and feeding have been described previously [8]. Briefly, four Bergamasca x Appenninica ruminally cannulated sheep (6 years old, with a mean body weight of $60.5 \pm 3.4 \mathrm{~kg}$ ) were used in a replicated $4 \times 4$ Latin square design. The experimental procedures and animal care conditions were approved by the Bioethics Committee of the University of Perugia and authorized by the Italian Ministry of Health. The animals were kept in four individual pens, with each pen fed one of the four treatment diets: 1) $1.5 \mathrm{~kg} / \mathrm{d}$ of alfalfa hay and $400 \mathrm{~g} / \mathrm{d}$ of concentrate pellet (CTR), 2) CTR supplemented with $7 \mathrm{~g} / \mathrm{d}$ of rosemary essential oil (EO) adsorbed onto inert material consisting of calcium carbonate and calcium and potassium aluminosilicate, 3) CTR with $10 \mathrm{~g} / \mathrm{d}$ of dried and ground rosemary leaves (RL), and 4) CTR with $10 \mathrm{~g} / \mathrm{d}$ of dried and ground rosemary leaves pelleted into concentrate (RL pellet). The diet composition was reported in Table 1 . Feed was offered twice daily in equal meals (8:00 and 16:00 h), and each treatment lasted for $21 \mathrm{~d}$. Different forms of rosemary supplementations (dry ground leaves, pelleted leaves, and essential oil extract) were evaluated because they differed in composition of secondary metabolites. Based on the rosemary EO content determined in a previous study [8], the amount of each form of rosemary supplementation fed to each sheep was calculated to give a dose of EO $(0.05 \mathrm{~g} / \mathrm{kg}$ of dry matter). To facilitate the introduction and mixing of the supplement in both the EO and RL diets, all feed ingredients were subjected to a rough grinding. Rumen content was sampled from each sheep before morning feeding from 3 different sites of the rumen after 21 days of adaptation on each diet and frozen immediately at $-80{ }^{\circ} \mathrm{C}$ until analyses.

\section{Metagenomic DNA extraction and quantitative real-time PCR analyses}

The rumen samples were processed as described by Mosoni et al. [14]. Briefly, the frozen rumen content samples were thawed at $4{ }^{\circ} \mathrm{C}$ overnight. For each rumen sample, $5 \mathrm{~g}$ of solid phase and $5 \mathrm{~g}$ of liquid phases were combined with $10 \mathrm{~mL}$ of sterile distilled water and homogenized for $10 \mathrm{~min}$ using a Stomacher (PBI International, Milan, Italy). The homogenate was centrifuged at $6,500 \times \mathrm{g}$ at $4{ }^{\circ} \mathrm{C}$ for $30 \mathrm{~min}$ and the supernatant was discarded. Metagenomic DNA extraction was performed using $0.25 \mathrm{~g}$ of the pellet obtained after centrifugation according the method of $\mathrm{Yu}$ and Morrison [15]. DNA quality was evaluated using agarose gel $(1 \%)$ electrophoresis and DNA yield was quantified using NanoDrop 2000 (Thermo Scientific, Wilmington, USA). The DNA samples were stored at $-20{ }^{\circ} \mathrm{C}$ until analysis.

All quantitative PCR (qPCR) analyses were performed on a Stratagene Mx3000p system (Stratagene Corporation, La Jolla, USA). Total bacterial population was quantified using a TaqMan assay, while the abundance of archaea, protozoa, and select bacterial species were quantified using SYBR Green-based specific qPCR assays. The primers and some of the PCR conditions used are shown in Table 2. One sample-derived qPCR standard was prepared for each target bacterial group using the respective specific PCR primer pair and a composite metagenomics DNA sample that was prepared by pooling an equal amount of all DNA samples as described previously [16]. After purification using a PCR 
Table 1 Ingredients (\% as fed basis) and chemical composition $(\mathrm{g} / 100 \mathrm{~g})$ of the concentrates used in the experimental diets (by Cobellis et al. [8])

\begin{tabular}{|c|c|c|c|c|}
\hline Item & Diet & & & \\
\hline Ingredients & CTR & RL pellet & $\mathrm{RL}$ & EO \\
\hline Wheat bran & 40.00 & 30.00 & 39.00 & 39.30 \\
\hline Wheat flour middlings & 17.80 & 24.30 & 17.35 & 17.49 \\
\hline Corn grain & 10.00 & 10.00 & 9.75 & 9.82 \\
\hline Sunflower meal & 14.90 & 14.90 & 14.53 & 14.64 \\
\hline Soybean meal & 5.00 & 6.00 & 4.87 & 4.91 \\
\hline Calcium carbonate & 4.20 & 4.20 & 4.09 & 4.13 \\
\hline Dehydrated alfalfa meal & 3.50 & 3.50 & 3.41 & 3.44 \\
\hline Beet protein concentrate & 2.00 & 2.00 & 1.95 & 1.96 \\
\hline Sugar cane molasses & 2.00 & 2.00 & 1.95 & 1.96 \\
\hline Vitamin-mineral supplement $^{1}$ & 0.60 & 0.60 & 0.60 & 0.60 \\
\hline Rosemary leaves & - & 2.50 & 2.50 & - \\
\hline Rosemary essential oil & - & - & - & 1.75 \\
\hline \multicolumn{5}{|l|}{ Chemical composition } \\
\hline \multicolumn{5}{|l|}{ Analysed } \\
\hline Dry matter & 92.88 & 92.78 & 92.84 & 92.96 \\
\hline Crude protein & 18.40 & 18.44 & 18.09 & 18.08 \\
\hline Crude fat & 3.08 & 3.21 & 3.12 & 3.05 \\
\hline Ash & 9.84 & 9.98 & 9.79 & 11.24 \\
\hline NDF & 29.65 & 29.52 & 29.79 & 29.13 \\
\hline ADF & 10.65 & 11.17 & 10.99 & 10.47 \\
\hline Lignin sa & 3.14 & 2.99 & 3.38 & 3.08 \\
\hline $\mathrm{Ca}$ & 0.80 & 0.70 & 0.79 & 0.79 \\
\hline$P$ & 0.75 & 0.68 & 0.75 & 0.74 \\
\hline $\mathrm{Na}$ & 0.28 & 0.27 & 0.27 & 0.28 \\
\hline \multicolumn{5}{|l|}{ Calculated } \\
\hline Lys & 0.70 & 0.71 & 0.68 & 0.69 \\
\hline Met & 0.29 & 0.29 & 0.28 & 0.28 \\
\hline Met + Cys & 0.58 & 0.58 & 0.56 & 0.57 \\
\hline Choline & 0.14 & 0.14 & 0.14 & 0.14 \\
\hline
\end{tabular}

${ }^{1}$ Supplied per kilogram of diet: Vitamin A, 18,000 I.U. (retinol); Vitamin $\mathrm{D}_{3}$, 2,100 I.U.; Vitamin E, $21 \mathrm{mg}$ (a-tocopheryl acetate); $\mathrm{Fe}, 29 \mathrm{mg}$; Co, $0.75 \mathrm{mg} ; \mathrm{Mn}$, $39 \mathrm{mg} ; \mathrm{Zn}, 150 \mathrm{mg}$; Se, $0.06 \mathrm{mg}$. CTR: control; RL pellet: CTR plus $10 \mathrm{~g} / \mathrm{d}$ of dried and ground rosemary leaves pelleted into concentrate; RL: CTR plus $10 \mathrm{~g} / \mathrm{d}$ of dried and ground rosemary leaves; EO: CTR plus $7 \mathrm{~g} / \mathrm{d}$ of rosemary essential oil adsorbed on an inert support

Purification kit (Qiagen, Valencia, USA) and quantification using a Quant-iT dsDNA broad-range assay kit (Invitrogen, Carlsbad, USA), rrs gene copy number concentration of each qPCR standard was calculated from its length and the mass concentration. Tenfold serial dilutions of each purified standard were prepared in TrisEDTA buffer prior to qPCR assays. In the SYBR-based qPCR assays, one $86{ }^{\circ} \mathrm{C}$ for $30 \mathrm{~s}$ step was added to each cycle and fluorescence signal was acquired at $86{ }^{\circ} \mathrm{C}$ to eliminate the effect from potential primer dimers [16]. Each qPCR assay was performed in triplicate for all samples and the respective $\mathrm{qPCR}$ standards using the same master mix and the same qPCR plate. The absolute abundance of each bacterial group was expressed as $\log _{10}$ of $r r s$ gene copies/g of rumen content.

\section{PCR-DGGE analysis}

Denaturing gradient gel electrophoresis (DGGE) was used to evaluate the overall response of bacterial and archaeal communities to rosemary supplements as described previously $[17,18]$. Briefly, the V3 hypervariable region of the $16 \mathrm{~S}$ rRNA gene of bacteria and archaea was amplified using bacterium- and archaeon-specific primers, with a 40-bp GC clamp added to the $5^{\prime}$ end of the forward primer (Table 2). The PCR and DGGE conditions and the gel image analysis were essentially the same as described previously [19].

\section{Statistical analysis}

All data were analysed as a $4 \times 4$ Latin square using the ANOVA procedure of SAS [20]. The statistical model included sheep, period, dietary treatment, and residual error. Fixed effects included period and dietary treatment. Sheep was the random effect. The abundances of rumen microbial populations (rrs gene copy number/g of rumen content) were first log-transformed prior to statistical analysis to improve normality. Overall differences between the means were evaluated using a Tukey test. Data were reported as least squares means \pm standard error. Differences were considered to be significant when $P \leq 0.05$. Based on the intensity and migration of the DGGE bands, a principal component analysis (PCA) was performed using the PC-ORD program as described by Patra and $\mathrm{Yu}$ [21] to analyze DGGE results.

\section{Results}

Abundance of rumen microbial populations

The results of the qPCR are shown in Table 3. Overall, the abundance of total bacteria, protozoa, and Ruminococcus flavefaciens was not affected by any of the rosemary supplements. The abundance of archaea and Prevotella spp. was, however, significantly decreased ( $P$ $<0.001)$ by the two diets containing rosemary leaves (RL or RL pellet). The RL diet also decreased $(P<0.001)$ the abundance of Ruminococcus albus and Clostridium aminophilum. The rosemary EO did not affect any of the quantified rumen microbial populations except for Fibrobacter succinogenes, which was increased $(P<$ $0.001)$ compared to the control. The abundance of total archaea was decreased by both RL and RL pellet but not by the rosemary essential oil. 
Table 2 Primers used to quantify ruminal microbes (qPCR) and to profile bacterial and archaeal communities (DGGE)

\begin{tabular}{|c|c|c|c|c|c|}
\hline Organisms & Primers & Sequences $\left(5^{\prime} \rightarrow 3^{\prime}\right)$ & $\begin{array}{l}\text { Annealing temperature, } \\
{ }^{\circ} \mathrm{C}\end{array}$ & $\begin{array}{l}\text { Amplicon length, } \\
\text { bp }\end{array}$ & References \\
\hline \multicolumn{6}{|l|}{ Real-time PCR } \\
\hline \multirow[t]{2}{*}{ Total bacteria } & $27 f$ & AGA GTT TGA TCM TGG CTC AG & 55 & 1535 & {$[41]$} \\
\hline & $1525 r$ & AAG GAG GTG WTC CAR CC & & & \\
\hline \multirow[t]{3}{*}{ Total bacteria } & Eub358f & TCC TAC GGG AGG CAG CAG T & 60 & 448 & {$[42]$} \\
\hline & Eub806r & GGA CTA CCA GGG TAT CTA ATC CTG TT & & & \\
\hline & $\begin{array}{l}\text { TaqMan } \\
\text { probe }\end{array}$ & $\begin{array}{l}\text { 6-FAM-5'-CGT ATT ACC GCG GCT GCT GGC } \\
\text { AC-3'-TAMRA }\end{array}$ & 70 & & \\
\hline \multirow[t]{2}{*}{ Archaea } & ARC787f & ATT AGA TAC CCS BGT AGT CC & 60 & 272 & {$[16]$} \\
\hline & ARC1059r & GCC ATG CAC CWC CTC T & & & \\
\hline \multirow[t]{2}{*}{ Protozoa } & $316 f$ & GCT TTC GWT GGT AGT GTA TT & 54 & 223 & {$[43]$} \\
\hline & $539 r$ & CTT GCC CTC YAA TCG TWC T & & & \\
\hline \multirow[t]{2}{*}{ Fibrobacter succinogenes } & Fs219f & GGT ATG GGA TGA GCT TGC & 63 & 446 & {$[44]$} \\
\hline & Fs654r & GCC TGC CCC TGA ACT ATC & & & \\
\hline \multirow[t]{2}{*}{ Ruminococcus flavefaciens } & Rf154f & TCT GGA AAC GGA TGG TA & 55 & 295 & {$[44]$} \\
\hline & Rf425r & CCT TTA AGA CAG GAG TाT ACA A & & & \\
\hline \multirow[t]{2}{*}{ Ruminococcus albus } & Ra1281f & CCC TAA AAG CAG TCT TAG TTC G & 55 & 175 & {$[44]$} \\
\hline & Ra1439r & CCT CCT TGC GGT TAG AAC A & & & \\
\hline \multirow[t]{2}{*}{ Prevotella spp. } & BAC303f & GAA GGT CCC CCA CAT TG & 56 & 418 & {$[45]$} \\
\hline & BAC708r & CAA TCG GAG TTC TTC GTG & & & \\
\hline \multirow[t]{2}{*}{ Clostridium aminophilum } & C.amin-57 F & ACG GAA ATT ACA GAA GGA AG & 57 & 560 & {$[46]$} \\
\hline & C.amin-616R & GTT TCC AAA GCA ATT CCA C & & & \\
\hline \multicolumn{6}{|l|}{ PCR-DGGE } \\
\hline \multirow[t]{2}{*}{ Total bacteria } & GC-A357f & CCC TAC GGG GCG CAG CAG & $61 \rightarrow 56^{\circ} \mathrm{C}$ & 194 & {$[17]$} \\
\hline & $519 r$ & GWA TTA CCG CGG CKG CTG & & & \\
\hline \multirow[t]{2}{*}{ Archaea } & GC-RC344f & ACG GGG YGC AGC AGG CGC GA & $61 \rightarrow 56^{\circ} \mathrm{C}$ & 191 & {$[18]$} \\
\hline & $519 r$ & GWA TTA CCG CGG CKG CTG & & & \\
\hline
\end{tabular}

FAM: 6-carboxyfluorescein; TAMRA: 6-carboxytetramethylrhodamine

Table 3 Effects of different rosemary supplements on select rumen microbial groups ( $\log _{10}$ rrs copies/g)

\begin{tabular}{|c|c|c|c|c|c|c|}
\hline & \multicolumn{4}{|l|}{ Diet } & \multirow[t]{2}{*}{ SEM } & \multirow[t]{2}{*}{$P$-value } \\
\hline & CTR & RL pellet & $\mathrm{RL}$ & $\mathrm{EO}$ & & \\
\hline Total Bacteria & 11.03 & 11.01 & 10.89 & 11.01 & 0.06 & 0.1994 \\
\hline Archaea & $8.86^{\mathrm{a}}$ & $8.69^{b}$ & $8.64^{b}$ & $8.80^{\mathrm{a}}$ & 0.05 & $<0.001$ \\
\hline Protozoa & $8.26^{\mathrm{ab}}$ & $7.71^{b}$ & $7.97^{\mathrm{b}}$ & $8.75^{\mathrm{a}}$ & 0.15 & $<0.001$ \\
\hline Prevotella spp. & $9.92^{\mathrm{a}}$ & $9.68^{b}$ & $9.72^{b}$ & $9.90^{\mathrm{a}}$ & 0.12 & $<0.01$ \\
\hline Fibrobacter succinogenes & $6.86^{\mathrm{b}}$ & $6.90^{\mathrm{ab}}$ & $6.88^{b}$ & $7.00^{\mathrm{a}}$ & 0.11 & $<0.001$ \\
\hline Ruminococcus albus & $7.62^{\mathrm{a}}$ & $7.67^{\mathrm{a}}$ & $7.27^{b}$ & $7.64^{a}$ & 0.16 & $<0.001$ \\
\hline Ruminococcus flavefaciens & $7.40^{\mathrm{ab}}$ & $7.59^{\mathrm{a}}$ & $7.59^{\mathrm{a}}$ & $7.43^{\mathrm{ab}}$ & 0.16 & $<0.05$ \\
\hline Clostridium aminophilum & $7.05^{\mathrm{a}}$ & $7.16^{\mathrm{a}}$ & $6.62^{\mathrm{b}}$ & $7.11^{\mathrm{a}}$ & 0.37 & $<0.001$ \\
\hline
\end{tabular}

${ }^{\mathrm{a}, \mathrm{b}}$ Means with different letters within a row differ significantly $(P \leq 0.05)$

CTR control; RL pellet: CTR plus $10 \mathrm{~g} / \mathrm{d}$ of dried and ground rosemary leaves pelleted into concentrate; RL: CTR plus $10 \mathrm{~g} / \mathrm{d}$ of dried and ground rosemary leaves; EO: CTR plus $7 \mathrm{~g} / \mathrm{d}$ of rosemary essential oil adsorbed on an inert support; NS not significantly 


\section{Community profiles of bacteria and archaea}

The DGGE profile of bacteria showed a large number of bands and a complex pattern (Fig. 1a). Differences in intensity of some bands were noted, but little difference in banding patterns was visible between the control and the treatments, suggesting minimal effects of the rosemary supplements on the ruminal bacterial community of the sheep. The first three principal components (PC's) together explained $71.61 \%$ of the total variation (Fig. 1b and c). No clear separation of bacterial community profiles between the control and any of the treatments along the first principal component (PC1) axis that explained more than $50 \%$ of the total variation. No separation of bacterial community profiles was seen along the second principal component ( $\mathrm{PC} 2)$ axis or the third principal component (PC3) axis, which explained 12.46 and $6.75 \%$ of the total variation, respectively.

The DGGE profiles of archaea showed a small number of bands, and no difference in number or intensity of bands was noticeable between the control and any of the treatments (Fig. 2a). The PC1, PC2, and $\mathrm{PC} 3$ together explained $78.26 \%$ of the total variation, and no separation of the archaeal community profiles was evident among the four different diet groups (Fig. 2b and c).

\section{Discussion}

In recent years, extracts from a variety of plants have been evaluated for their ability to modulate rumen microbiome, feed digestion, and rumen fermentation. Some plant compounds have been revealed to affect the abundance and/or the activity of rumen archaea, protozoa, and specific bacteria populations [5, 21-24]. Rosemary contains a number of antimicrobial monoterpenoids and phenolic diterpenes and rosemary supplements can potentially modify rumen functions. Their biological activity can be variable but several studies documented their specific activity on growth and energy metabolism of microbial cells [5].

A large number of in vitro and in vivo studies have been performed to test the ability of plant extracts to modulate rumen microbiome, to our knowledge; however, this is the first in vivo study to evaluate the effects of rosemary supplementations in different forms on rumen bacteria and archaea using cultivationindependent molecular biology techniques. In a previous study, we showed that rosemary leaves and essential oil decreased $\mathrm{CP}$ and DM digestibility and tended to lower rumen ammonia concentration in sheep [8]. In the present study, the abundance of Prevotella and protozoa (though only numerically) was lowered by rosemary leaves, ether in pellet (RL pellet) or in loose form (RL),
(A)

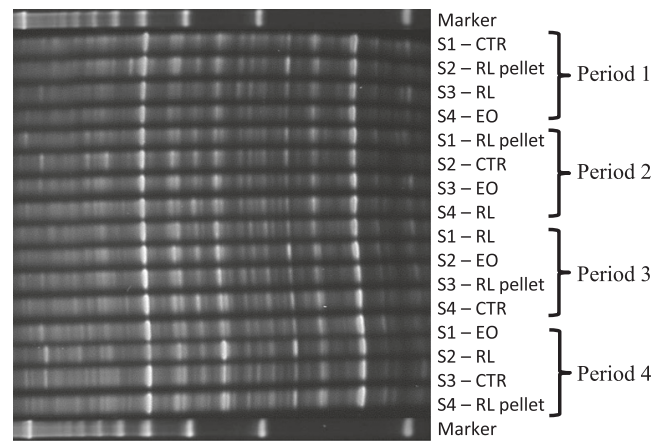

(B)

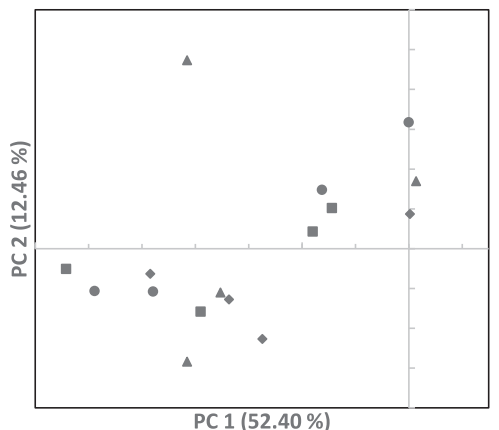

(C)

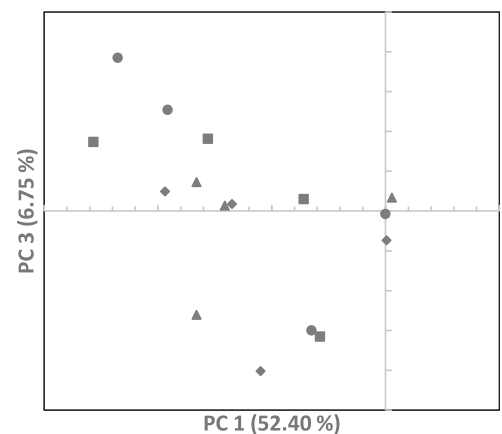

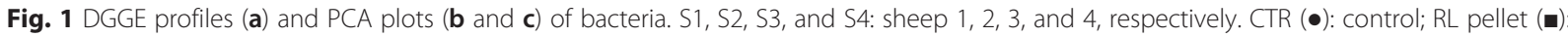
CTR plus $10 \mathrm{~g} / \mathrm{d}$ of dried and ground rosemary leaves pelleted into the concentrate; RL ( $)$ : CTR plus $10 \mathrm{~g} / \mathrm{d}$ of dried and ground rosemary leaves; EO $(\boldsymbol{\Lambda}):$ CTR plus $7 \mathrm{~g} / \mathrm{d}$ of rosemary essential oil adsorbed on an inert support 
(A)

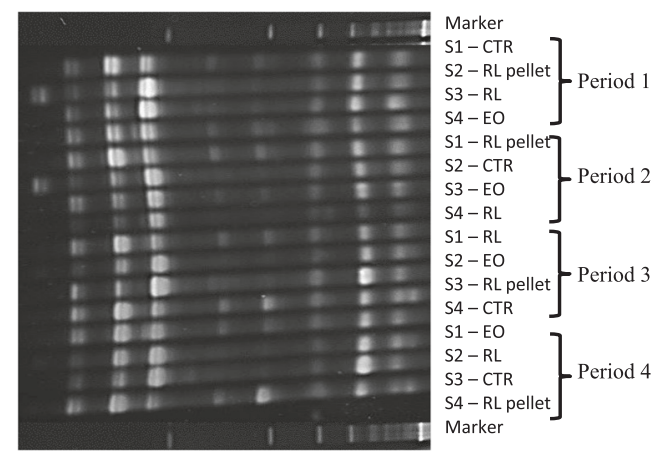

(B)

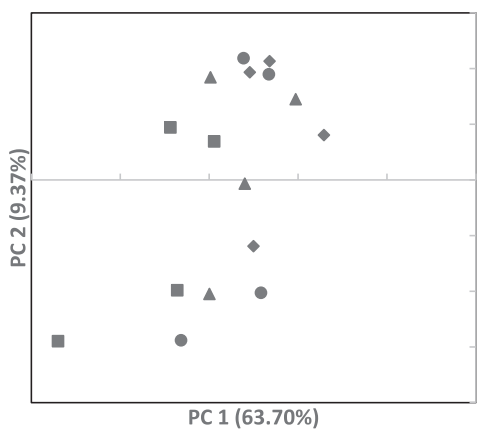

(C)

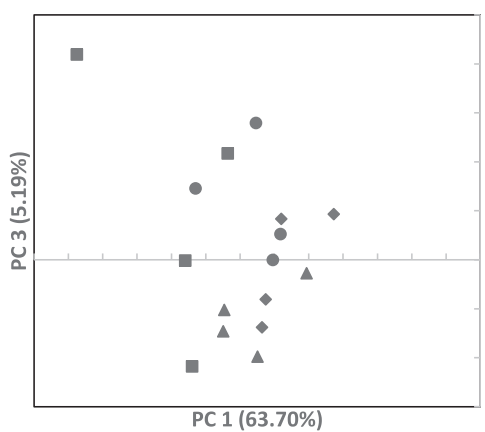

Fig. 2 DGGE profiles (a) and PCA plots of archaea (b and c). S1, S2, S3, and S4: sheep 1, 2, 3, and 4, respectively. CTR (•): control; RL pellet ( $\bullet$ ) CTR plus $10 \mathrm{~g} / \mathrm{d}$ of dried and ground rosemary leaves pelleted into the concentrate; RL ( $\mathbf{}$ ): CTR plus $10 \mathrm{~g} / \mathrm{d}$ of dried and ground rosemary leaves; EO ( $\mathbf{\Delta})$ : CTR plus $7 \mathrm{~g} / \mathrm{d}$ of rosemary essential oil adsorbed on an inert support

and RL also decreased the population of C. aminophilum (Table 3). Because members of Prevotella and protozoa are the mainly proteolytic microbes and $C$. aminophilum is one the three well documented hyperammonia-producing bacterial species [25], the decreased CP digestibility observed in the previous study [8] might be attributed to the decrease of these microbial groups. By the same token, the lower DM degradation could be related to the reduction of the abundance of Prevotella and Ruminococcus albus (Table 3).

The abundance of the analyzed microbial groups was affected by any of the rosemary leaves, but essential oil at the tested dose increased the abundance of F. succinogenes (Table 3). The differential effects between rosemary leaves and essential oil could be related to differences in the chemical composition of their antimicrobial compounds, with phenolic diterpenes, such as carnosic acid and rosmarinic acid, being rich in rosemary leaves, while rosemary essential oil is rich in monoterpenoids [8]. According to a number of studies [26-28], rumen microbes can adapt to essential oils, especially at low levels. One mechanism is reduction of active components of essential oils to inert alcohols by some microbes [29]. Indeed, Bernardes et al. [30] showed that the antimicrobial activity of extracts from rosemary leaves could be ascribed mainly to carnosic acid and carnosol, while rosmarinic acid has no antimicrobial activity against selected bacteria. However, a few studies showed that both rosmarinic and carnosic acids have antioxidant and antimicrobial activities [31, 32], and interestingly, rosemary extracts with similar rosmarinic acid content but different ratios of two phenolic diterpenes, carnosic acid and carnosol, differed in antibacterial activities. These observations suggest chemical interactions among different secondary metabolites and such interaction may affect the antimicrobial potency of rosemary extracts. In addition, some of the monoterpenoids in rosemary essential oil have a fairly broad range of antimicrobial activity [31, 33-35]. Some of these compounds are chemically instable and/or high volatile [36]. The lack of effect of the rosemary essential oil observed in the present study might result from loss of some instable or volatile antimicrobial compounds.

The rosemary leave supplementation, either in loose form or in pellet, decreased the abundance of archaea. However, the magnitude of the decrease in archaeal abundance is relatively small. Ohene-Adjei et al. [37] suggested that a reduction in the abundance of methanogen could be observed after prolonged inhibition of methane synthesis. Indeed, lack of decrease in archaeal abundance by anti-methane inhibitors has been observed in short-term in vitro incubation $[21,22,38]$. In 
addition, although not reaching statistical significance, the rosemary leaves also only lowered the abundance of rumen protozoa, potentially decreasing protozoaassociated methanogens and their contribution to methane production. Furthermore, the ability of rosemary leaves to decrease the abundance of $R$. albus, a hydrogen-producing bacterial species, points toward a potential to lower production of hydrogen, the electron donor of methanogenesis. Therefore, rosemary leaves, as suggested by some authors for other plant extracts [3, 37-39], may directly inhibit methanogenic archaea and inhibit some microbial metabolic processes contributing to methane production.

As revealed by DGGE analyses, no significant effect on the overall bacterial or archaeal communities was noted from any of the rosemary supplements at the tested doses (Figs. 1 and 2). The lack of apparent broad effect on bacterial or archaeal communities is consistent with the similar total bacterial abundance in the control and the rosemary treatments. DGGE can only detect some predominant members of microbial communities, and thus some of the affected members might have not been detected by the DGGE analysis. In addition, after a period of adaptation, some rumen microbes could acquire the capability of degrading and inactivating plant compounds [40], and variations among individual animals could also 'hide' dietary effects. However, many aspects about the relationship between dietary components and rumen microbiome are still poorly understood (such as similar fermentation characteristics of cows fed the same diet but with different rumen microbiome structure). For this reason, further efforts will be required to identify safe and effective compounds able to positively affect rumen microbial ecosystem and its fermentation, reducing the production of pollutants (methane and ammonia) by decreasing the abundance of the microbes that are involved in methane and ammonia production in the rumen.

\section{Conclusion}

This study demonstrated that dietary supplementation with rosemary leaves can affect the abundance of several groups of rumen microbes that are known to be involved in degradation of protein and fiber and production of methane and ammonia. Given the potential effects on rumen fermentation, future studies are warranted to further evaluate rosemary supplementation in modulating rumen microbiome and modifying rumen function, especially methane production and nitrogen excretion.

\section{Competing interests}

None of the authors has any financial or personal interest that would inappropriately influence or bias the contents of this paper.

\section{Authors' contributions}

GC, GA and CF performed the animal study and collected the rumen samples. MTM, GA and ZY were responsible for experimental design. GC performed all laboratory analysis and ZY supervised all laboratory work. MTM, CF and GC performed statistical analysis. GC and ZY drafted and revised the manuscript. All authors read and approved the final manuscript for publication.

\section{Acknowledgements}

This research was sponsored by the IZSUM 004/09 RC project funded by the Italian Ministry of Health (MinSal). G. Cobellis's tenure at The Ohio State University was supported by a grant from the University of Perugia (PhD research project in Animal Health, Livestock Production and Food Safety, XXVIII cycle). This work was partially supported by the National Institute of Food and Agriculture, U.S. Department of Agriculture, under award number 2012-67015-19437. The authors would like to thank G. Alunni for help in laboratory analyses and G. Ponti, A. Mazzoccanti and G. Covarelli for assistance and care of the animals. Conagit S.p.A. and APA-CT srl are gratefully acknowledged for providing technical support and advice in formulating experimental feeds.

Received: 23 October 2015 Accepted: 17 April 2016

Published online: 27 April 2016

\section{References}

1. Hristov AN, Oh J, Firkins JL, Dijkstra J, Kebreab E, Waghorn G, et al. Special topics - Mitigation of methane and nitrous oxide emissions from animal operations: I. A review of enteric methane mitigation options. J Anim Sci. 2013:91:5045-69.

2. Patra AK. Enteric methane mitigation technologies for ruminant livestock: a synthesis of current research and future directions. Environ Monit Assess. 2012:184:1929-52.

3. Patra AK, Saxena J. A new perspective on the use of plant secondary metabolites to inhibit methanogenesis in the rumen. Phytochem. 2010; 71:1198-222.

4. Hart KJ, Yanez-Ruiz DR, Duval SM, McEwan NR, Newbold CJ. Plant extracts to manipulate rumen fermentation. Anim Feed Sci Technol. 2008;147:8-35.

5. Cobellis G, Trabalza-Marinucci M, Yu Z. Critical evaluation of essential oils as rumen modifiers in ruminant nutrition: A review. Sci Total Environ. 2016;545: 556-68.

6. Patra AK, Yu Z. Effective reduction of enteric methane production by a combination of nitrate and saponin without adverse effect on feed degradability, fermentation, or bacterial and archaeal communities of the rumen. Bioresour Technol. 2013;148:352-60.

7. Patra AK, Yu Z. Effects of garlic oil, nitrate, saponin and their combinations supplemented to different substrates on in vitro fermentation, ruminal methanogenesis, and abundance and diversity of microbial populations. J Appl Microbiol. 2015;119:127-38.

8. Cobellis $G$, Acuti $G$, Forte $C$, Menghini L, De Vincenzi S, Orrù M, et al. Use of Rosmarinus officinalis in sheep diet formulations: Effects on ruminal fermentation, microbial numbers and in situ degradability. Small Rumin Res. 2015;126:10-8.

9. Cobellis $G$, Petrozzi A, Forte $C$, Acuti $G$, Orrù M, Marcotullio $M C$, et al. Evaluation of the effects of mitigation on methane and ammonia production by using Origanum vulgare L. and Rosmarinus officinalis L. essential oils on in vitro rumen fermentation systems. Sustainability. 2015; 7:12856-69.

10. Roy D, Tomar SK, Sirohi SK, Kumar V, Kumar M. Efficacy of different essential oils in modulating rumen fermentation in vitro using buffalo rumen liquor. Vet World. 2014;7:213-8.

11. Castillejos $L$, Calsamiglia S, Martín-Tereso J, Ter Wijlen H. In vitro evaluation of effects of ten essential oils at three doses on ruminal fermentation of high concentrate feedlot-type diets. Anim Feed Sci Technol. 2008;145:259-70.

12. Gunal M, Ishlak A, Abughazaleh AA. Evaluating the effects of six essential oils on fermentation and biohydrogenation in in vitro rumen batch cultures. Czech J Anim Sci. 2013;58:243-52.

13. Jahani-Azizabadi H, Danesh Mesgaran M, Vakili SA, Rezayazdi K, Hashemi M. Effect of various medicinal plant essential oils obtained from semi-arid climate on rumen fermentation characteristics of a high forage diet using in vitro batch culture. African J Microb Res. 2011;5:4812-19. 
14. Mosoni P, Chaucheyras-Durand F, Béra-Maillet C, Forano E. Quantification by real-time PCR of cellulolytic bacteria in the rumen of sheep after supplementation of a forage diet with readily fermentable carbohydrates: effect of a yeast additive. J Appl Microbiol. 2007;103:2676-85.

15. Yu Z, Morrison M. Improved extraction of PCR-quality community DNA from digesta and fecal samples. Biotechniques. 2004;36:808-13.

16. Yu Z, Michel Jr FC, Hansen G, Wittum T, Morrison M. Development and application of real-time PCR assays for quantification of genes encoding tetracycline resistance. Appl Environ Microbiol. 2005;71:6926-33.

17. $\mathrm{Yu} Z$ Z, Morrison M. Comparisons of different hypervariable regions of rrs genes for use in fingerprinting of microbial communities by PCR-denaturing gradient gel electrophoresis. Appl Environ Microbiol. 2004;70:4800-6.

18. Yu Z, Garcia-Gonzalez R, Schanbacher FL, Morrison M. Evaluations of different hypervariable regions of archaeal 16S rRNA genes in profiling of methanogens by archaea-specific PCR and denaturing gradient gel electrophoresis. Appl Environ Microbiol. 2008;74:889-93.

19. Cressman MD, Yu Z, Nelson MC, Moeller SJ, Lilburn MS, Zerby HN Interrelations between the microbiotas in the litter and in the intestines of commercial broiler chickens. Appl Environ Microbiol. 2010;76:6572-82.

20. SAS Institute Inc. JMP®9 Basic Analysis and Graphing. Cary: SAS Institute Inc:; 2010.

21. Patra AK, Yu Z. Effects of essential oils on methane production and fermentation by, and abundance and diversity of, rumen microbial populations. Appl Environ Microbiol. 2012;78:4271-80.

22. Patra AK, Yu Z. Effects of adaptation of in vitro rumen culture to garlic oil, nitrate and saponin and their combinations on methanogenesis, fermentation, and abundances and diversity of microbial populations. Front Microbiol. 2015;6:1434

23. McIntosh FM, Williams P, Losa R, Wallace RJ, Beever DA, Newbold CJ. Effects of essential oils on ruminal microorganisms and their protein metabolism. Appl Environ Microbiol. 2003;69:5011-14.

24. Benchaar C, Greathead H. Essential oils and opportunities to mitigate enteric methane emissions from ruminants. Anim Feed Sci Technol. 2011; 166:338-55.

25. Firkins $J$, Yu Z, Morrison M. Ruminal nitrogen metabolism: perspectives for integration of microbiology and nutrition for dairy. J Dairy Sci. 2007:90:1-16.

26. Cardozo PW, Calsamiglia S, Ferret A, Kamel C. Effects of natural plant extracts on ruminal protein degradation and fermentation profiles in continuous culture. J Anim Sci. 2004;82:3230-6.

27. Cardozo PW, Calsamiglia S, Ferret A, Kamel C. Effects of alfalfa extract, anise, capsicum, and a mixture of cinnamaldehyde and eugenol on ruminal fermentation and protein degradation in beef heifers fed a highconcentrate diet. J Anim Sci. 2006;84:2801-8.

28. Busquet M, Calsamiglia S, Ferret A, Cardozo PW, Kamel C. Effects of cinnamaldehyde and garlic oil on rumen microbial fermentation in a dual flow continuous culture. J Dairy Sci. 2005;88:2508-16.

29. Chizzola R, Hochsteiner W, Hajek S. GC analysis of essential oils in the rumen fluid after incubation of Thuja orientalis twigs in the Rusitec system. Res Vet Sci. 2004;76:77-82.

30. Bernardes WA, Lucarini R, Tozatti MG, Souza MG, Andrade Silva ML, da Silva Filho AA, et al. Antimicrobial activity of Rosmarinus officinalis against oral pathogens: relevance of carnosic acid and carnosol. Chem Biodivers. 2010;7: 1835-40.

31. Klančnik A, Guzej B, Hadolin Kolar M, Abramovič H, Možina SS. In vitro antimicrobial and antioxidant activity of commercial rosemary extract formulations. J Food Prot. 2009;72:1744-52.

32. Moreno S, Scheyer T, Romano CS, Vojnov AA. Antioxidant and antimicrobial activities of rosemary extracts linked to their polyphenol composition. Free Radical Res. 2006:40:223-31.

33. Smith-Palmer A, Stewart J, Fyfe L. Antimicrobial properties of plant essential oils and essences against five important food-borne pathogens. Lett Appl Microbiol. 1998;26:118-22.

34. Elgayyar M, Draughon FA, Golden DA, Mount JR. Antimicrobial activity of essential oils from plants against selected pathogenic and saprophytic microorganisms. J Food Prot. 2001;64:1019-24

35. Santoyo S, Cavero S, Jaime L, Ibanez E, Senorans FJ, Reglero G. Chemical composition and antimicrobial activity of Rosmarinus officinalis L. essential oil obtained via supercritical fluid extraction. J Food Prot. 2005;68:790-5.

36. Turek C, Stintzing FC. Stability of essential oils: a review. Compr Rev Food Sci Food Saf. 2013:12:40-53.
37. Ohene-Adjei S, Chaves AV, McAllister TA, Benchaar C, Teather RM, Forster RJ. Evidence of increased diversity of methanogenic archaea with plant extract supplementation. Microb Ecol. 2008;56:234-42.

38. Patra AK, Yu Z. Combinations of nitrate, saponin, and sulfate additively reduce methane production by rumen cultures in vitro while not adversely affecting feed digestion, fermentation or microbial communities. Bioresour Technol. 2014;155:129-35.

39. Beauchemin KA, McGinn SM. Methane emissions from beef cattle: effects of fumaric acid, essential oil, and canola oil. J Anim Sci. 2006;84:1489-96.

40. Broudiscou LP, Cornu A, Rouzeau A. In vitro degradation of 10 mono- and sesquiterpenes of plant origin by caprine rumen micro-organisms. J Sci Food Agric. 2007;87:1653-8.

41. Lane DJ. 16S/23S rRNA sequencing. In: Stackebrandt E, Goodfellow M editors. Nucleic Acid Techniques in Bacterial Systematics. Chichester: John Wiley and Sons; 1991. p. 115-75.

42. Nadkarni MA, Martin FE, Jacques NA, Hunter N. Determination of bacterial load by real-time PCR using a broad-range (universal) probe and primers set. Microbiol. 2002;148:257-66.

43. Sylvester JT, Karnati SK, Yu Z, Morrison M, Firkins JL. Development of an assay to quantify rumen ciliate protozoal biomass in cows using real-time PCR. J Nutr. 2004;134:3378-84.

44. Koike S, Kobayashi Y. Development and use of competitive PCR assays for the rumen cellulolytic bacteria: Fibrobacter succinogenes, Ruminococcus albus and Ruminococcus flavefaciens. FEMS Microbiol Lett. 2001;204:361-6.

45. Stiverson J, Morrison M, Yu Z. Populations of select cultured and uncultured bacteria in the rumen of sheep and the effect of diets and ruminal fractions. Int J Microbiol. 2011;2011:750613.

46. Patra AK, Yu Z. Effects of vanillin, quillaja saponin, and essential oils on in vitro fermentation and protein-degrading microorganisms of the rumen. Appl Microbiol Biotechnol. 2014;98:897-905.

\section{Submit your next manuscript to BioMed Central and we will help you at every step:}

- We accept pre-submission inquiries

- Our selector tool helps you to find the most relevant journal

- We provide round the clock customer support

- Convenient online submission

- Thorough peer review

- Inclusion in PubMed and all major indexing services

- Maximum visibility for your research

Submit your manuscript at www.biomedcentral.com/submit
) Biomed Central 